\title{
Synthesis, Characterization, Biological Activity and DNA Cleavage Studies on Tetrazole Imine Base and Their Metal Complexes - An Experimental and Theoretical Approach
}

\author{
Ranjithreddy Palreddy ${ }^{\mathbf{1}}$, Jaheer Mohmed ${ }^{\mathbf{1}}$, Narsimha Nagula ${ }^{\mathbf{1}}$, Banoth Srinivas ${ }^{2}$, \\ Ch. Sarala Devi ${ }^{1^{*}}$. \\ ${ }^{I}$ Department of Chemistry, Osmania University, Hyderabad-500 007, A. P, India. \\ ${ }^{2}$ Department of Microbiology, Osmania University, Hyderabad-500 007, A. P, India.
}

\begin{abstract}
Novel Tetrazole imine and its binary $\mathrm{Cu}(\mathrm{II})$ and $\mathrm{Ni}(\mathrm{II})$ complexes were synthesized and characterized by employing spectro - analytical techniques viz; Mass, UV, IR, ${ }^{1} H$ NMR, elemental analyses, thermo-analytical methods, SEM and magnetic susceptibility measurements. The equilibrium studies were carried out using pH-metric technique to get an insight of the number of dissociable protons and protonation sites in candidate compound. The pH-Metric studies were also carried out in presence of metal ions to establish the formation of corresponding metal complexes in solution. To understand the frontier orbitals in title imine compound suitable for metal ion coordination, the computational studies were carried out by employing HyperChem 7.5 tools. The energies of HOMO and LUMO frontier orbitals were computed with geometry optimized molecules. The antimicrobial studies carried out by screening the tetrazole imine base and their metal complexes against bacteria inferred positive results. The DNA cleavage studies on title compound and its metal complexes using PBR322 DNA indicated that the tetrazole imine base has no role in cleavage of DNA and in its metal complexes, only $\mathrm{Cu}(\mathrm{II})$ complex played marked role in cleavage.
\end{abstract}

KEY WORDS: Novel tetrazole imines, Binary Cu (II) and Ni (II) complexes, Computational studies, DNA cleavage, Spectro-analytical studies.

\section{INTRODUCTION}

Tetrazoles have a wide range of applications in pharmaceutical science. There is considerable interest in the medicinal and biological applications of tetrazoles [1] including 5-aminotetrazoles, due to their reported anti-allergic, anti-asthmatic [2-3], antiviral, anti-inflammatory [4], anti-neoplastic [5], and cognition disorder activities [6]. Tetrazoles are also applied as ligands in coordination chemistry [7-9], as explosives and rocket propellants [10-12]. Tetrazole derivatives are potential compounds for drug development for HIV or other immune diseases [13-14]. In general, metal complexes can often cause DNA damage in cancer cells arresting the division of cancer cells resulting in cell death [15-17]. Literature survey reveals that no work has been reported on title compound 2-((E)-(1-phenyl-1H-tetrazol-5-ylimino) methyl) phenol (PTP) with respect to its synthesis, characterization and its chelation properties. Further the biological activity and DNA cleavage studies have not been explored till date. Keeping in view the significant role of imine bases of tetrazoles and its metal complexes in various fields, in the present study, we have synthesized novel tetrazole imine base 2-((E)-(1phenyl-1H-tetrazol-5-ylimino)methyl)phenol(PTP) and its $\mathrm{Cu}(\mathrm{II})$ and $\mathrm{Ni}(\mathrm{II})$ complexes. The characterization of tetrazole imine (PTP) and its metal complexes have been carried out by employing spectro-analytical techniques and further anti-bacterial activity and DNA cleavage studies were also studied.

\section{EXPERIMENTAL}

2.1 Synthesis of 2-((E)-(1-phenyl-1H-tetrazol-5-ylimino) methyl) phenol (PTP)

Equimolar ratios $(0.02 \mathrm{~mol})$ of 1-phenyl-1H-tetrazol-5-amine and 2-hydroxy benzaldehyde were dissolved in methanol $(10 \mathrm{ml})$ and the reaction mixture was refluxed for 3 to $4 \mathrm{hrs}$ at $60-70{ }^{\circ} \mathrm{C}$. The reaction progress was monitored by TLC. The solid obtained was filtered, washed with methanol and recrystallized from aqueous ethanol to obtain pure compound (yield $=58 \%$ and m.p. 194). 
<smiles>Nc1nnnn1-c1ccccc1</smiles>

2.2 Preparation of metal complexes

To a solution of the imine base PTP in chloroform, methanolic solutions of the metal chlorides, $\mathrm{Cu}$ (II) and $\mathrm{Ni}$ (II), were added drop wise. The metal complexes were obtained by stirring the mixture on magnetic stirrer for $10-12$ hours at $50-60{ }^{\circ} \mathrm{C}$. The separated metal complexes were washed with chloroform and methanol (yield $=85 \%, 80 \%$ and m.p. > 300).

\section{PHYSICAL MEASUREMENTS}

All chemicals used are AR grade. IR spectra $(\mathrm{KBr})$ were recorded on a Perkin-Elmer 337 Spectrophotometer. The UV-Visible spectra were recorded on a Schimadzu UV spectrophotometer in the wavelength range $200-900 \mathrm{~nm}$. ${ }^{1} \mathrm{H}-\mathrm{NMR}$ spectra has been recorded on Varian Gemini unity spectrometer and Mass spectra on VG AUTOSPEC. The Particle size and morphology of title compound and its complexes were recorded on Zeiss Scanning Electron Microscope. INCA EDX instrument was used for the elemental analyses. The magnetic susceptibility measurements were made on a Faraday balance model 7550 . The thermal studies were carried out using Shimadzu TGA-50H in nitrogen atmosphere. Melting points and decomposition temperature of complexes were determined on polmon instrument (Model No.MP-90).

\section{COMPUTATIONAL STUDIES}

The computational studies were carried out by using HyperChem 7.5 software. The molecule was built using HyperChem 7.5 software and the geometry optimization was carried out using PM3 method. The heats of formation, dipole moments, eigen values of HOMO \& LUMO and QSAR properties are computed from these studies

\section{RESULTS \& DISCUSSION}

The title compound and its metal complexes have been characterized using spectro-analytical tools viz; IR, mass, ${ }^{1} \mathrm{H}-\mathrm{NMR}$ and $\mathrm{D}_{2} \mathrm{O}$ exchange ${ }^{1} \mathrm{HNMR}$. Thermo-analytical and magnetic moment data of complexes have also been recorded.

\subsection{Characterization of PTP}

Mass spectral data

The mass spectrum of PTP exhibits (Fig 1) a dominant base peak at $\mathrm{m} / \mathrm{z} 266$ which is in accordance with the theoretical mass.

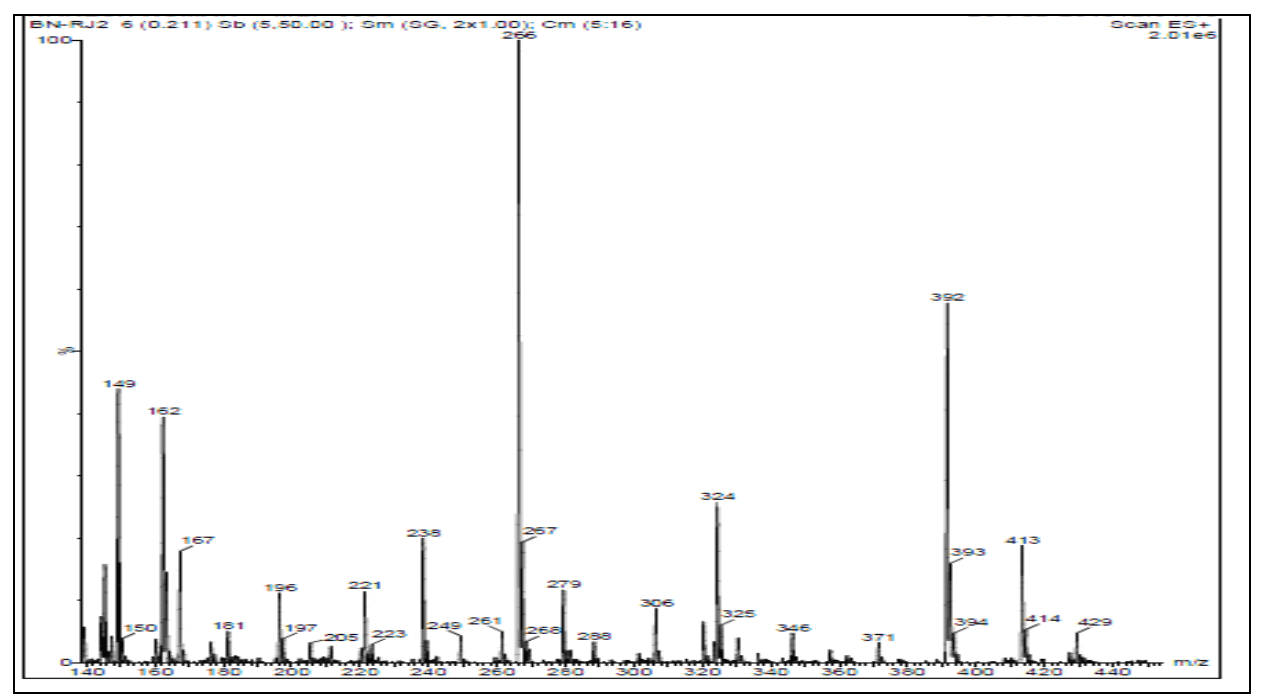

Figure 1: Mass spectrum of PTP 


\subsubsection{IR spectral data}

The IR spectrum of PTP displayed bands at 3492 and $3062 \mathrm{~cm}^{-1}$ corresponding to the $\mathrm{OH}$ and $\mathrm{CH}$ stretching frequencies. A band at $1666 \mathrm{~cm}^{-1}$ can be attributed to $\mathrm{C}=\mathrm{N}$ stretching frequency (Fig 2).

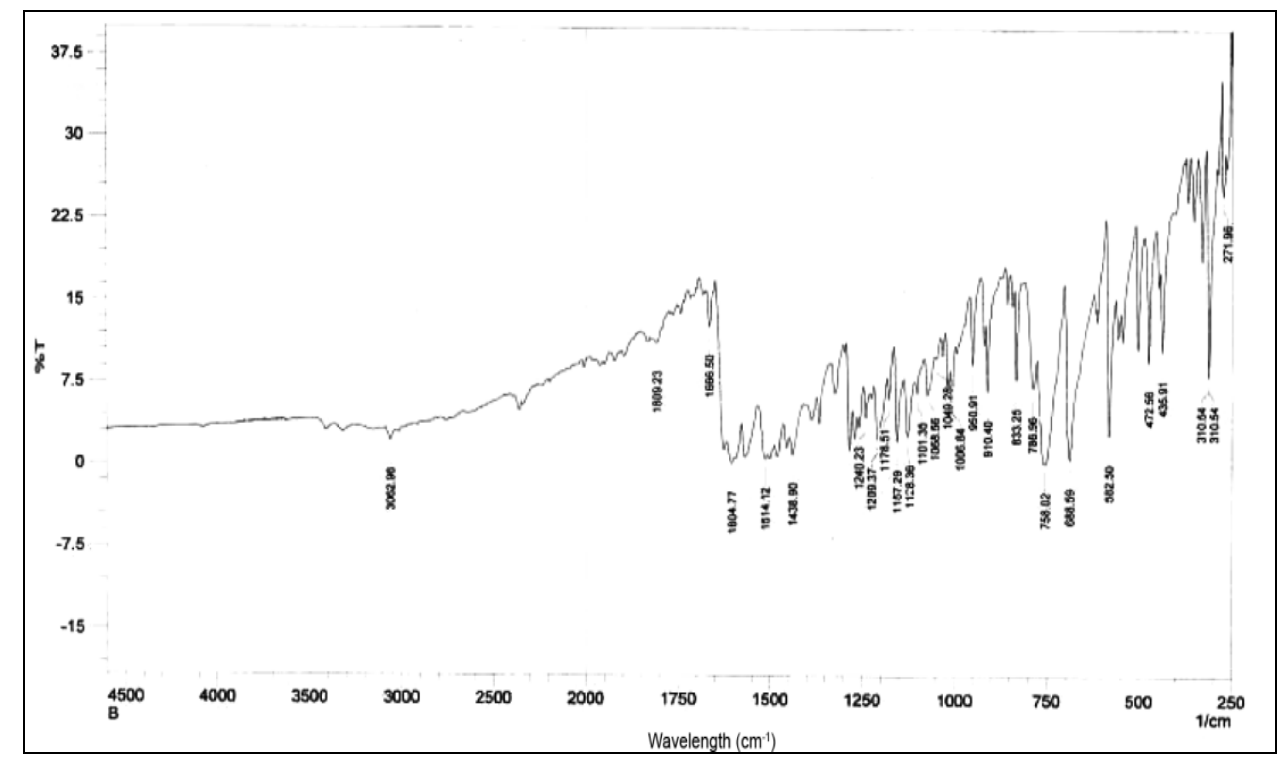

\subsection{3 ${ }^{1} \mathrm{H}$ NMR spectral data}

Figure 2: IR Spectrum of PTP

The proton NMR spectrum of 2-((E)-(1-phenyl-1H-tetrazol-5-ylimino)methyl) phenol (Fig 3) was recorded in $\mathrm{CDCl}_{3}$. The signal corresponding to the $\mathrm{OH}$ proton was recorded at $\delta 11.5 \mathrm{ppm}(\mathrm{s}, 1 \mathrm{H})$ and signal for the azomethine proton at $9.25(\mathrm{~s}, 1 \mathrm{H}) \mathrm{ppm}$. The signals for the aromatic protons were seen in the range 7.1 $8.2(\mathrm{~m}, 9 \mathrm{H}) \mathrm{ppm}$. The $\mathrm{OH}$ signal was identified by its disappearance in the $\mathrm{D}_{2} \mathrm{O}$ exchange spectrum (Fig 4).

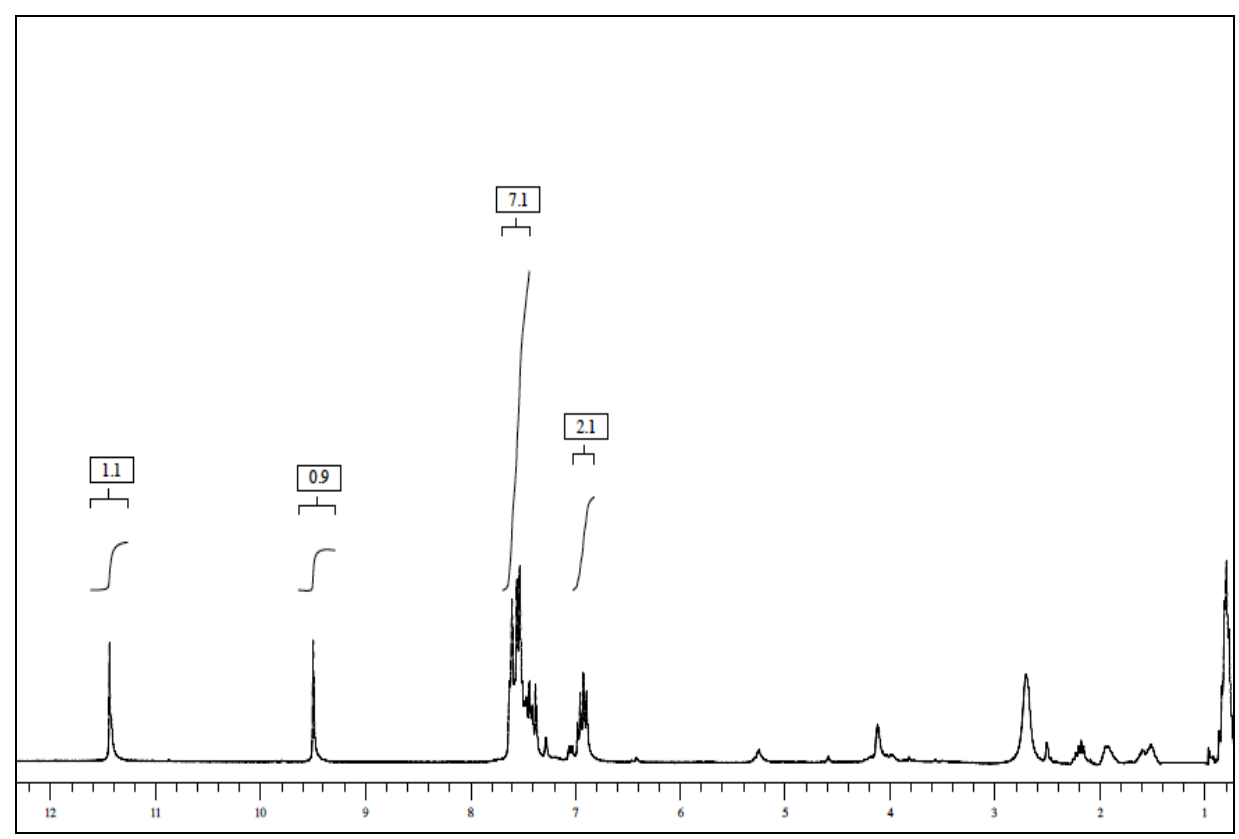

Figure 3: NMR spectrum of PTP 


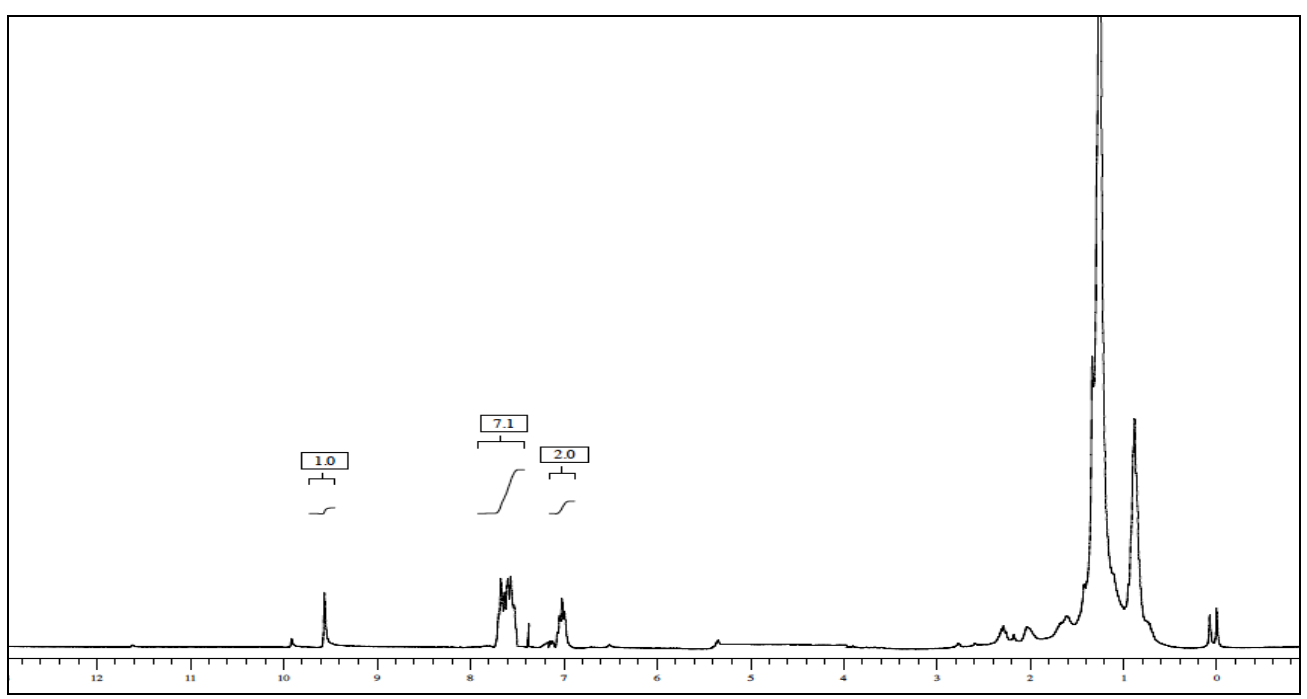

Figure 4: $\mathrm{D}_{2} \mathrm{O}$ exchange ${ }^{1} \mathrm{H}-\mathrm{NMR}$ spectrum of PTP

\subsubsection{Electronic spectral data}

The UV spectrum for PTP displayed absorption peaks at 290 and $370 \mathrm{~nm}$ which are due to $\pi-\pi^{*}$ and $\mathrm{n}-\pi^{*}$ transitions (Fig 5).

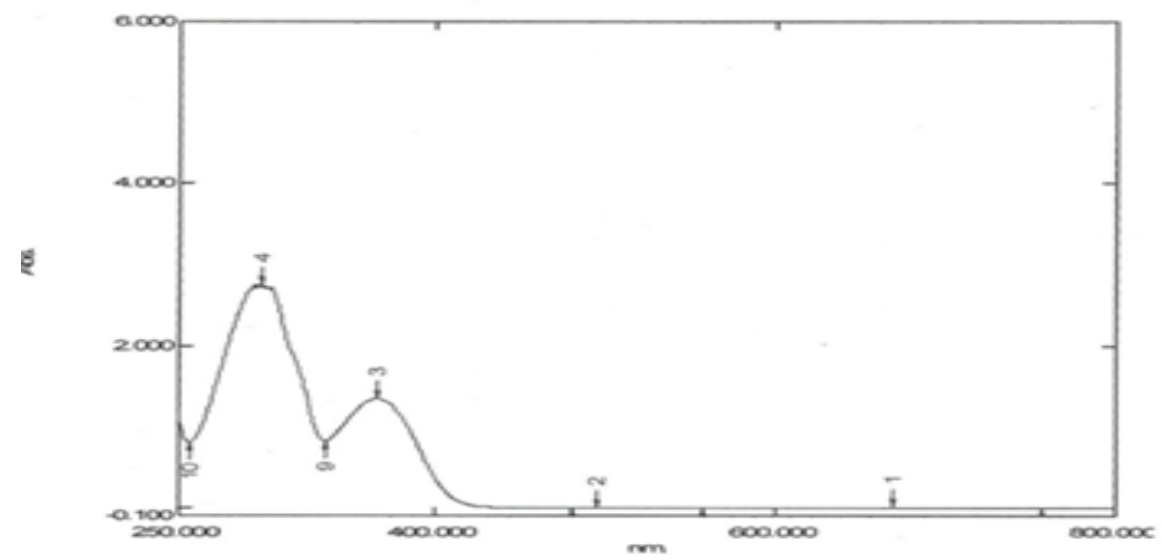

Figure 5: UV spectrum of PTP

\subsection{Equilibrium studies}

As the title compound is one of the analogues of tetrazoles, which are DNA cleavage agents, in the present investigation, to study its chelation properties, an attempt is made to understand the potential donor sites which can bind with the metal ions. Further, to ascertain metal chelation, it is prerequisite to determine the dissociation constants of dissociable protons and protonation constants if the molecule has protonation sites. In the present study, Irving-Rossotti $\mathrm{pH}$ titration technique was employed for the determination of dissociation constants as the candidate compound has dissociable protons. The $\mathrm{pH}$-metric titrations were carried out in $70 \%$ dioxan-water medium at $303 \mathrm{~K}$ and $0.1 \mathrm{M}\left(\mathrm{KNO}_{3}\right)$ ionic strength. The dissociation constant values were calculated using Irving-Rossotti titration technique [18-25]. From the titration data obtained, dissociation constants have been calculated from the linear plot of $\log \left(1-\bar{n}_{\mathrm{A}}\right) / \bar{n}_{\mathrm{A}} \mathrm{Vs} \mathrm{pH}$ (Fig 7). The results indicated the presence of one dissociable proton corresponding to phenolic OH group of PTP $(p \mathrm{Ka}=10.08)$. The $\quad \mathrm{pH}-$ metric titrations were also carried out in presence of metal ions with title compound in $70 \%$ dioxan- water medium at $303 \mathrm{~K}$ and $0.1 \mathrm{M}\left(\mathrm{KNO}_{3}\right)$ ionic strength (Fig.6). The titration curves clearly indicated the release of dissociable proton more easily in presence of metal ions indicating formation of corresponding complexes in solution. 


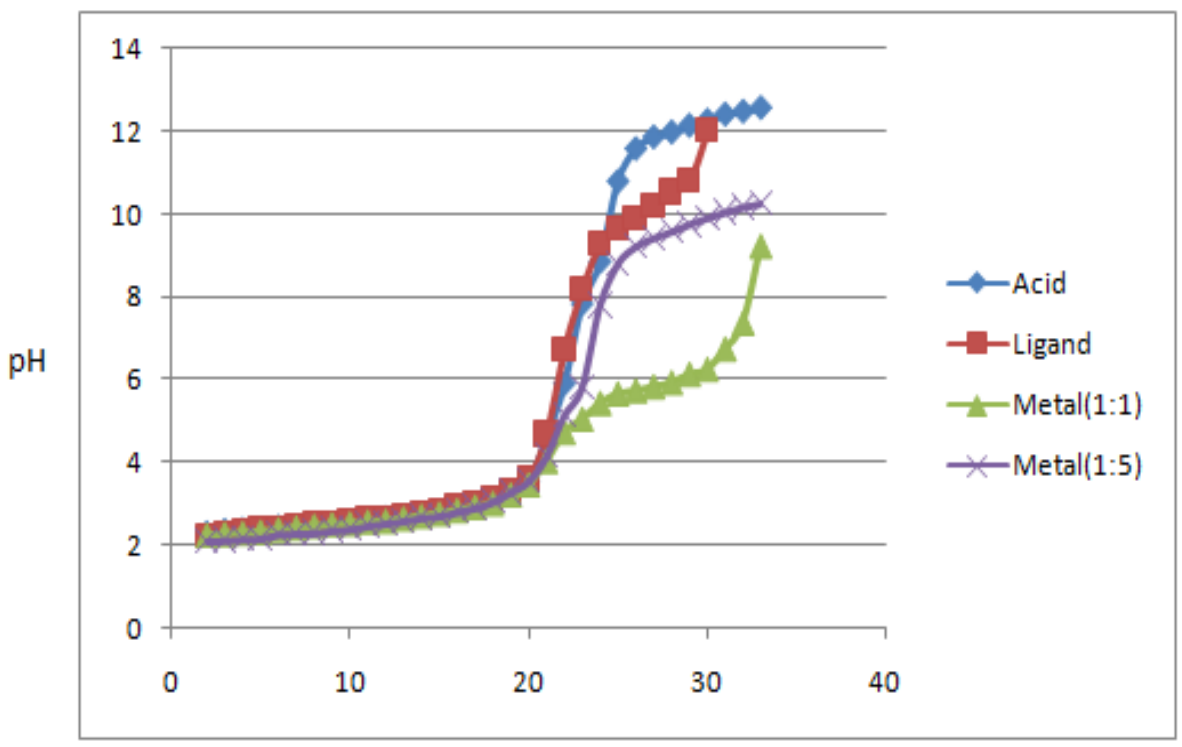

Vol of $\mathrm{NaOH}$

Figure 6: pH titration curves of Cu (II) PTP binary system in 70\% v/v Dioxan-water medium at $303 \mathrm{~K}$ and $0.1 \mathrm{M}$ ionic strength.

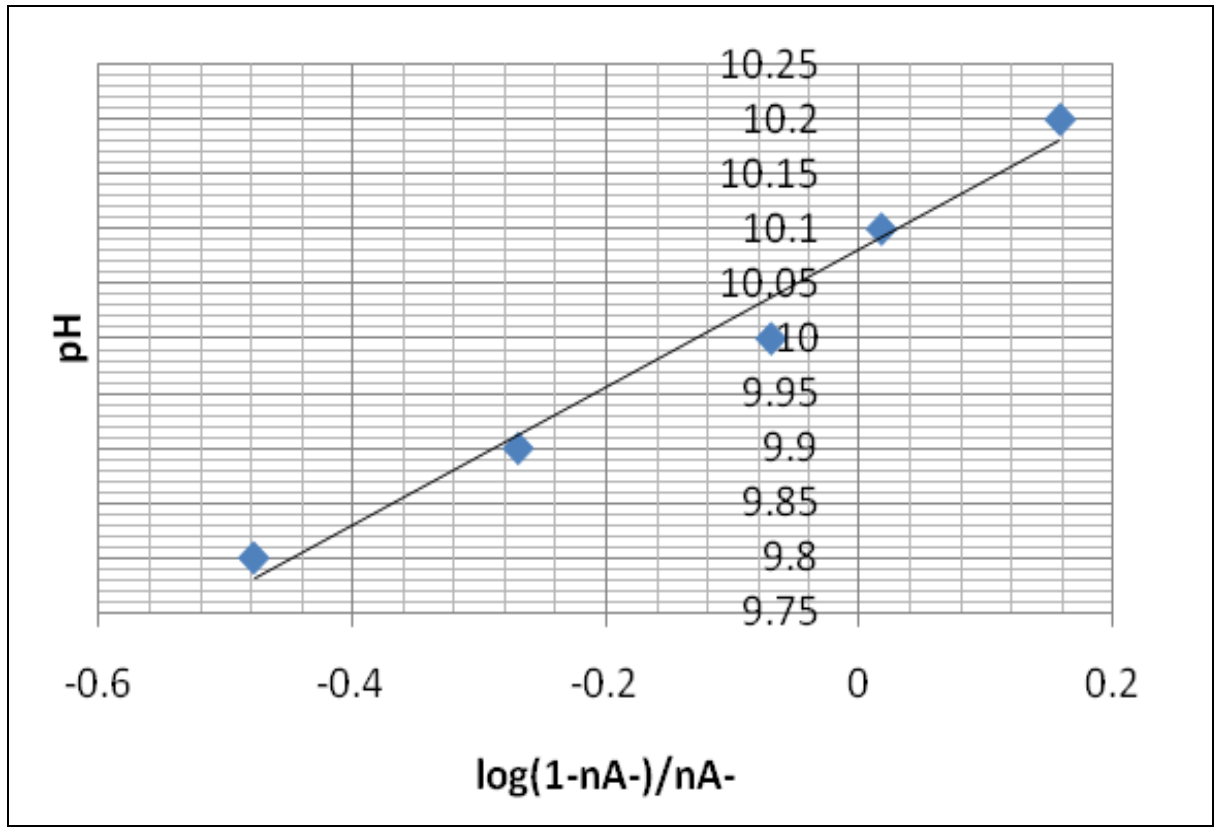

Figure 7: Plots of $\log \left(1-\bar{n}_{\mathrm{A}}\right) /\left(\bar{n}_{\mathrm{A}}\right)$ Vs pH of PTP in 70\% v/v Dioxan - water medium.

\subsection{Characterization of Copper and Nickel complexes of PTP}

\subsubsection{Mass spectral data}

The mass spectra of the copper (Fig 8) and nickel (Fig 9) complexes displayed peaks at m/z 385 and $\mathrm{m} / \mathrm{z} 639$ corresponding to molecular quasi ion peaks of $\mathrm{Cu}$ (II) PTP and Ni (II) PTP complexes. 


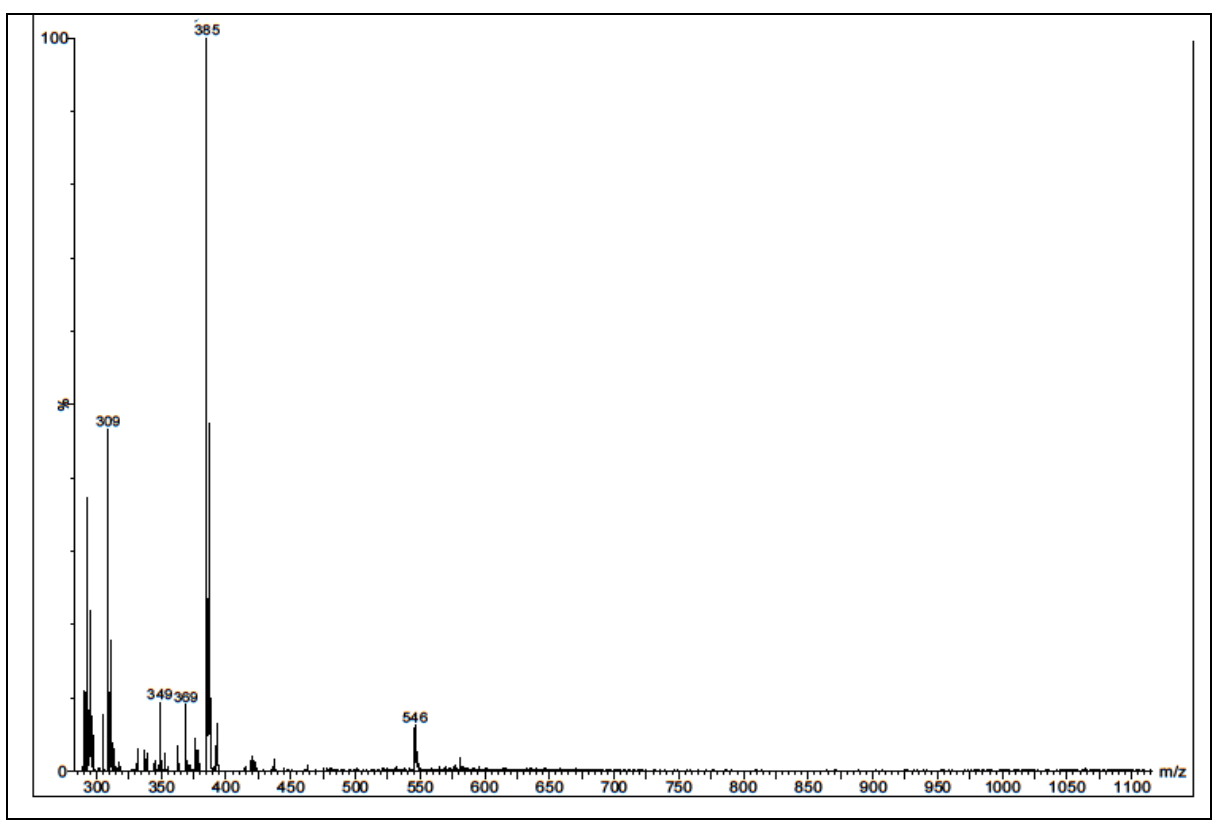

Figure 8: Mass Spectrum of Cu (II)-PTP Complex

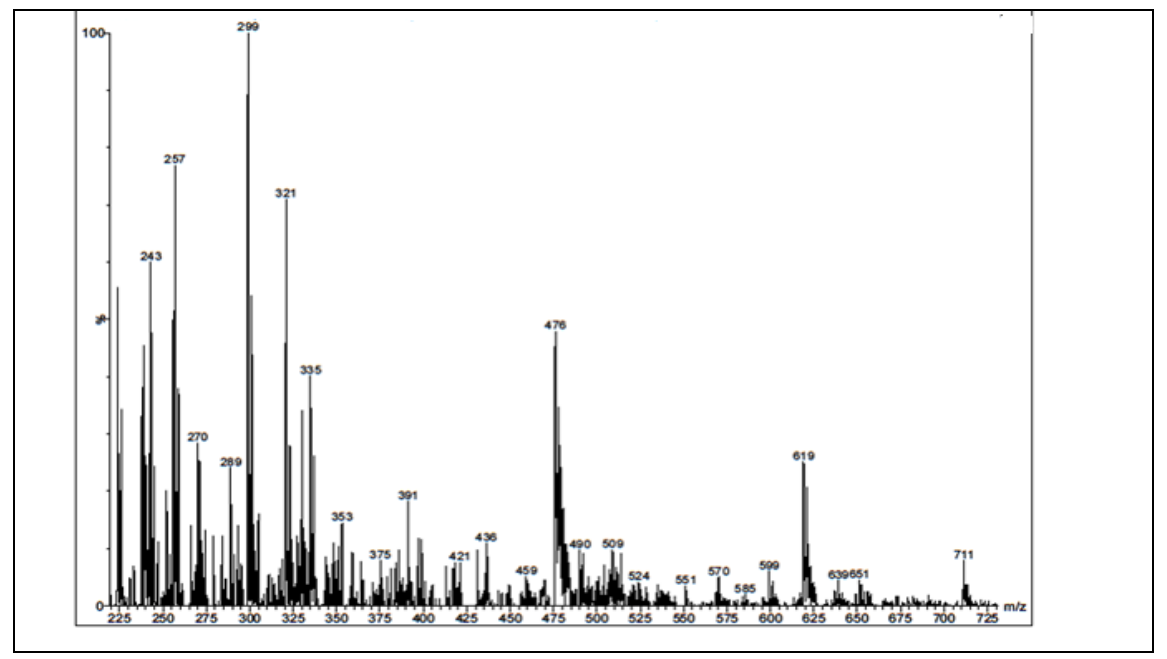

Figure 9: Mass Spectrum of Ni(II)-PTP Complex

\subsubsection{IR spectral data}

The IR spectra provided valuable information about the type of donor sites attached to the metal ion in a complex. The main IR stretching frequencies and their assignments for PTP and its complexes are listed in Table 1.

Table 1: FT-IR spectral Data of PTP and its complexes

\begin{tabular}{|c|c|c|c|c|}
\hline & $\mathbf{v}_{\mathbf{C H}=\mathbf{N}}$ & $\mathbf{v}_{\mathbf{M}-\mathbf{N}}$ & $\mathbf{v}_{\mathbf{M}-\mathbf{O}}$ & $\mathbf{v}_{\mathbf{O H} / \mathbf{H} 20}$ \\
\hline $\mathbf{P T P}$ & 1666 & - & - & 3492 \\
\hline $\mathbf{N i}(\mathbf{I I}) \mathbf{P T P}$ & 1618 & 468 & 596 & 3304 \\
\hline $\mathbf{C u}(\mathbf{I I}) \mathbf{P T P}$ & 1631 & 474 & 555 & 3404,3221 \\
\hline
\end{tabular}

The $\mathrm{HC}=\mathrm{N}$ stretching frequency in the IR spectrum of PTP was observed at $1666 \mathrm{~cm}^{-1}$. This band was shifted towards lower frequency $\left(1618\right.$ and $\left.1631 \mathrm{~cm}^{-1}\right)$ in the IR spectra of the metal complexes (Fig 10 \& 11$)$ indicating the participation of $(\mathrm{CH}=\mathrm{N})$ nitrogen in coordination $(\mathrm{M}-\mathrm{N})$ with the metal. Broad bands in the range $3220-3400 \mathrm{~cm}^{-1}$ are due to presence of coordinated water molecule present in metal complexes. In addition, new bands around $550-596$ and $460-475 \mathrm{~cm}^{-1}$ corresponding to $\mathbf{v}_{\mathbf{M}-\mathbf{N}}, \mathbf{v}_{\mathbf{M}-\mathrm{o}}$ were observed in IR spectra of the metal complexes. 


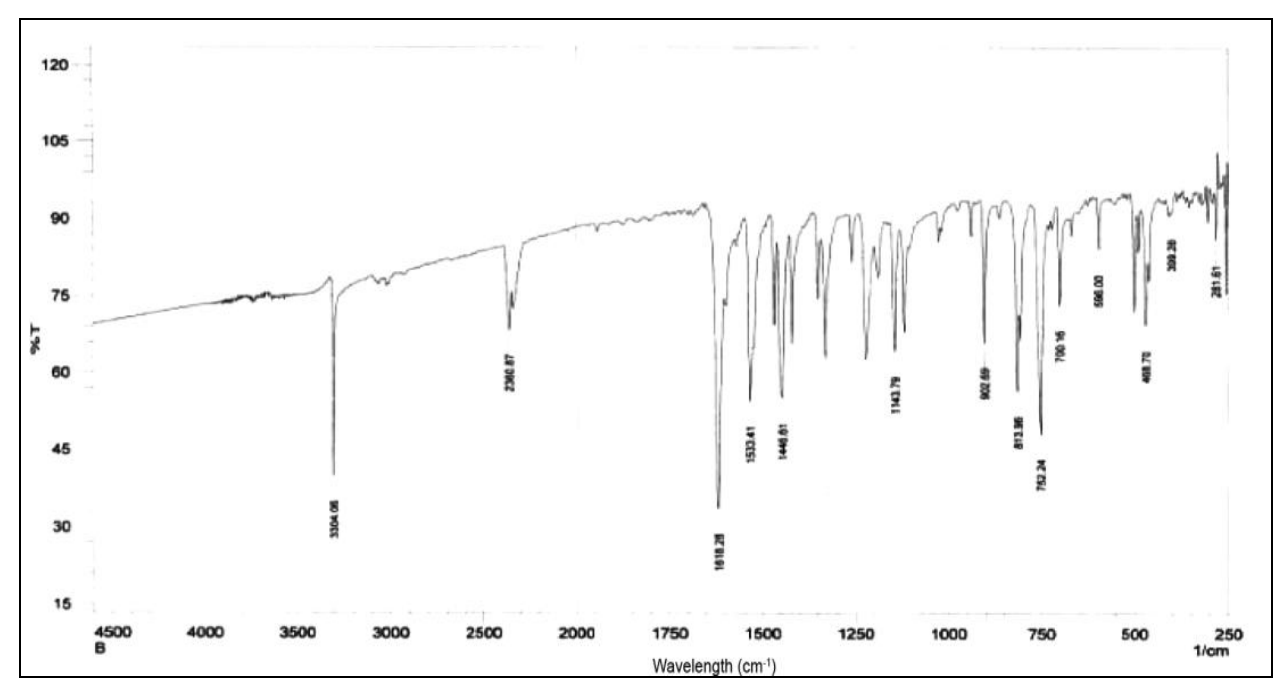

Figure 10: IR Spectrum of Ni(II)complex

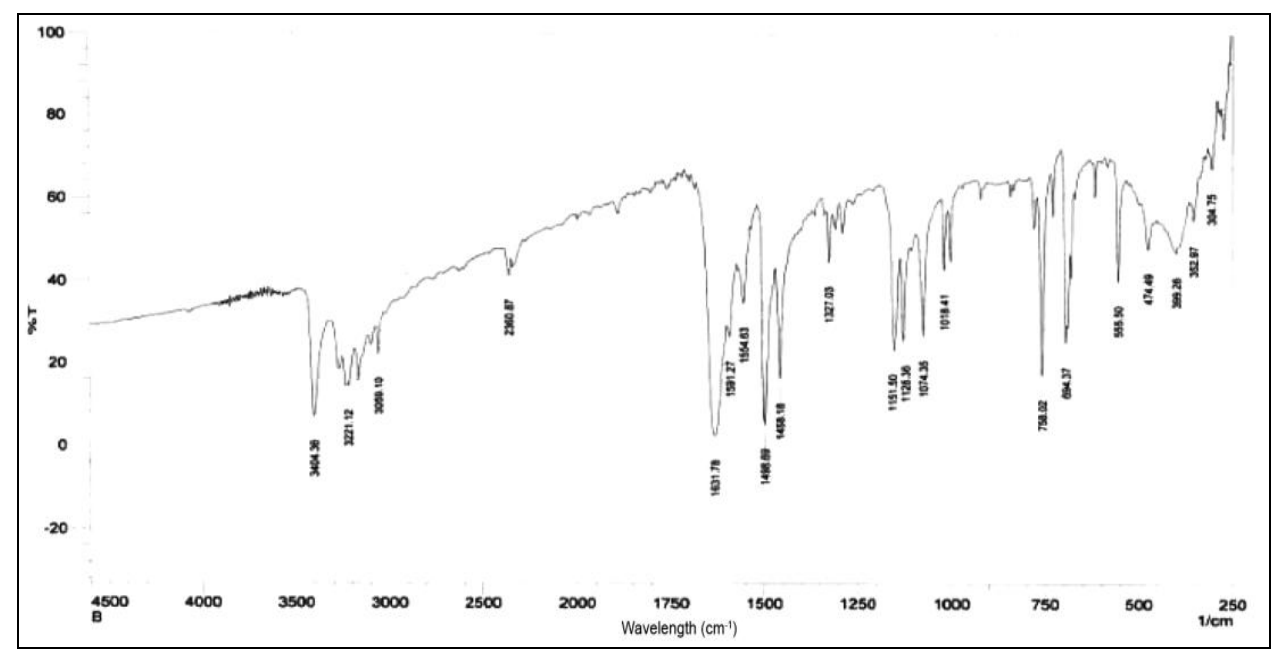

Figure 11: IR Spectrum of $\mathrm{Cu}(\mathrm{II})$ complex

\subsubsection{Electronic Spectra}

The UV-Visible spectra of PTP and its complexes of $\mathrm{Cu}$ (II) and Ni (II) were recorded in DMSO. The absorption peaks recorded at 408 and $735 \mathrm{~nm}$ in the UV spectrum of Ni (II) PTP complex (Fig 12) are attributable to d-d transitions.
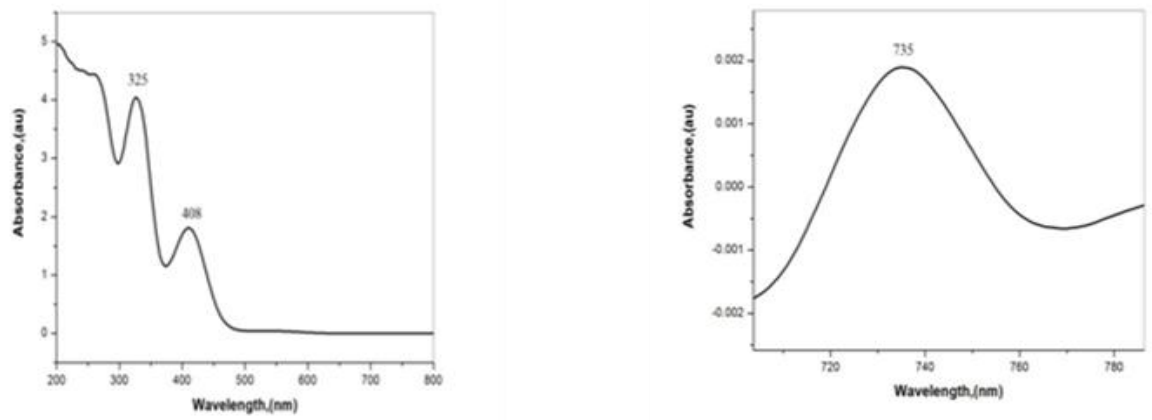

Figure 12: UV spectrum of Ni (II) PTP complex 


\subsubsection{SEM and EDX of PTP and its complexes}

The PTP, its Cu (II) and Ni (II) complexes showed different morphologies (Fig13, 14and 15). The SEM of PTP appeared as needle type particles with a size in the range of $200 \mu \mathrm{m}$. After the formation of the complex, the needle type particles were changed to irregular and rod type with the particle size in the range of $100 \mu \mathrm{m}$. EDX method is used to identify the elements which are present in PTP and its $\mathrm{Cu}$ (II) and Ni (II) complexes.
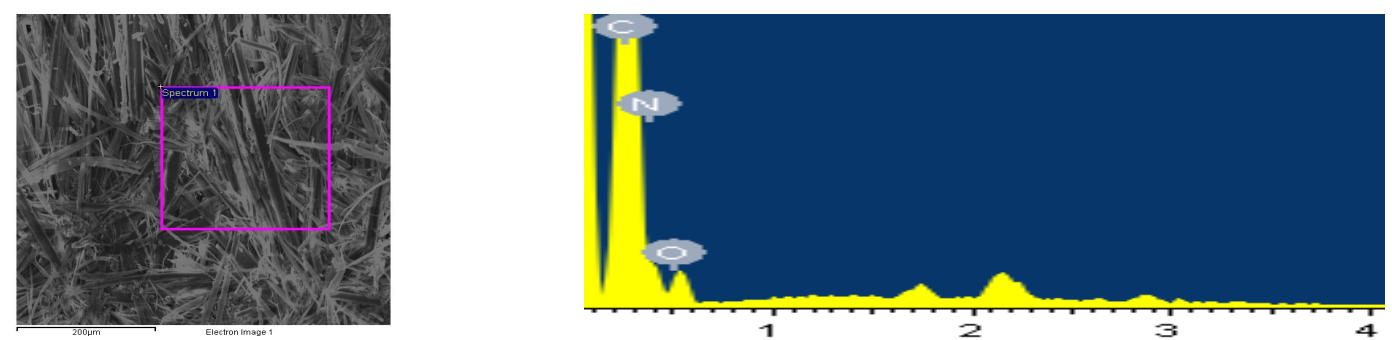

Figure 13: SEM Image and EDX spectrum of PTP
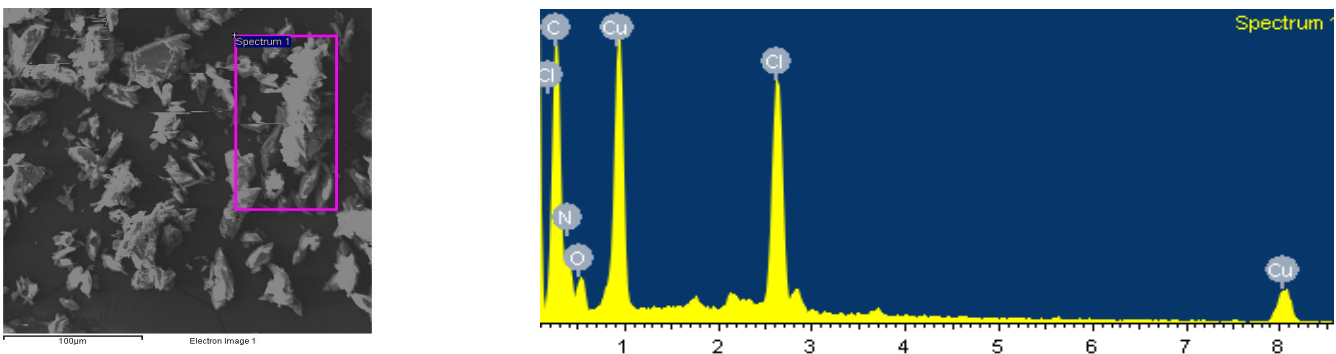

Figure 14: SEM Image and EDX spectrum of Cu (II) PTP
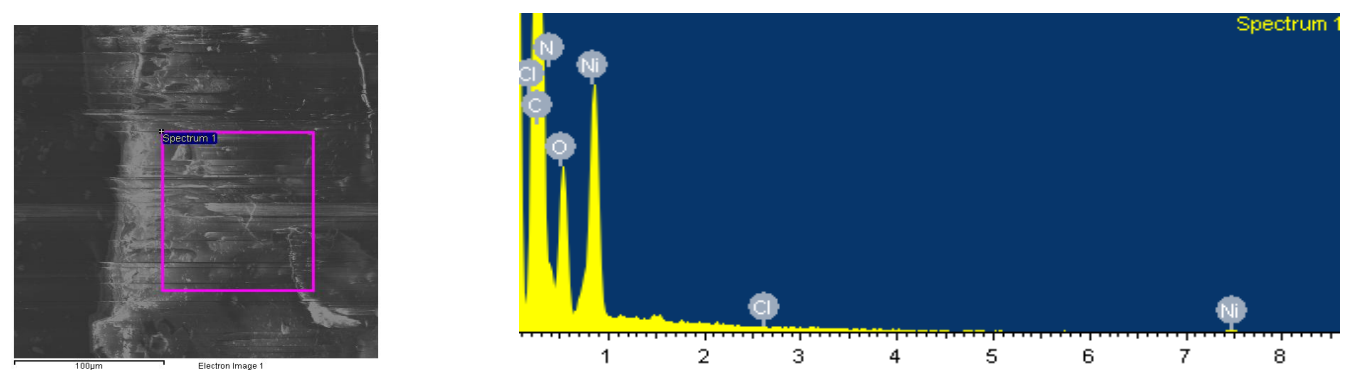

Figure 15: SEM Image and EDX spectrum of Ni (II) PTP

\subsubsection{Thermo-analytical Studies}

Thermo-gravimetric analysis (TG) and Differential Thermal Analysis (DTA) were performed on the copper and nickel complexes of PTP. The TGA curve for $\mathrm{Cu}$ (II) PTP complex (Fig 16) exhibited weight loss around $150{ }^{\circ} \mathrm{C}$ corresponding to the loss of coordinated water. The DTA curve of the complex exhibits an endothermic peak at $\mathrm{t}_{\min }=233{ }^{\circ} \mathrm{C}$. The next step of decomposition from $250{ }^{\circ} \mathrm{C}$ to $600{ }^{\circ} \mathrm{C}$ corresponds to loss of the ligand moiety and an exothermic peak in DTA at $\mathrm{t}_{\min }=570{ }^{\circ} \mathrm{C}$ may be due to change in crystal structure. Above $600{ }^{\circ} \mathrm{C}$, the curve indicated slight increase of weight with a residual mass of $33.4 \%$ corresponding to the formation of metal oxide. The DTA exothermic peaks indicate explosive or pyrolytic nature of tetrazole imine base moiety. 


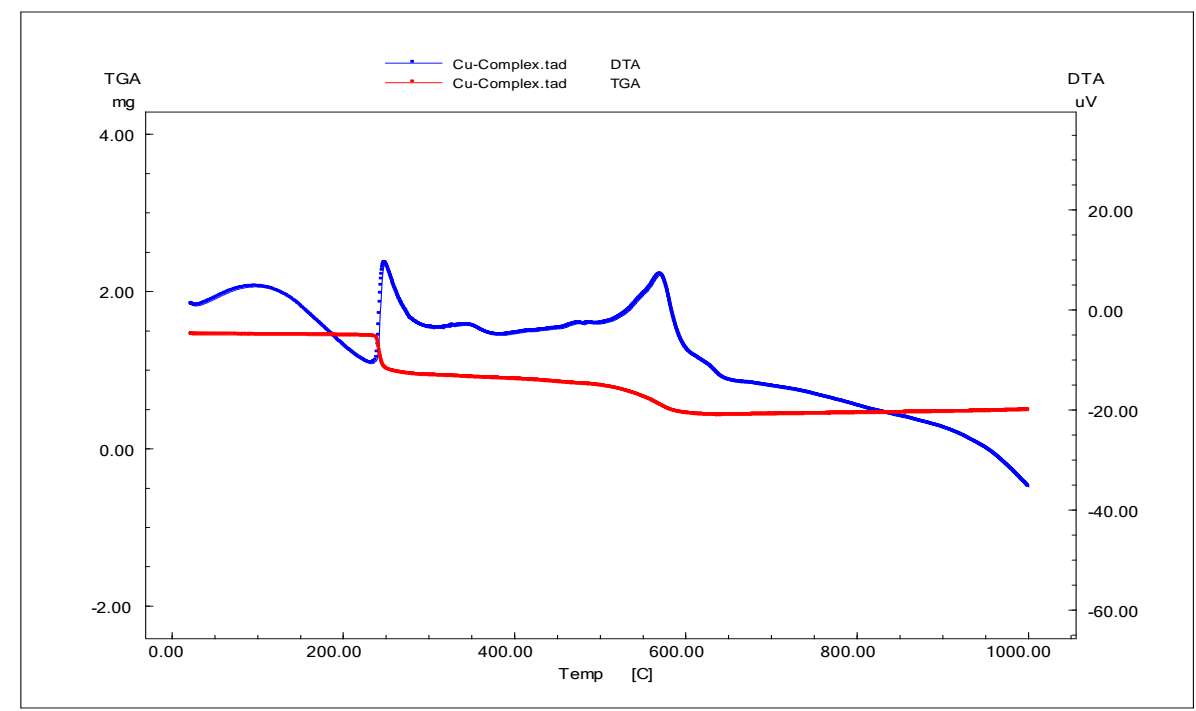

Figure 16: TGA and DTA curves of Cu (II) PTP complex.

$\mathrm{Ni}$ (II) PTP complex (Fig 17) exhibited weight loss in the temperature range $200{ }^{\circ} \mathrm{C}$ to $340{ }^{\circ} \mathrm{C}$, the DTA curve of the complex exhibits an exothermic peak at $\mathrm{t}_{\min }=338^{\circ} \mathrm{C}$ corresponding to the loss of the coordinated water molecule and ligand moiety. The next step of decomposition is seen in the range $350{ }^{\circ} \mathrm{C}$ to $400{ }^{\circ} \mathrm{C}$; the final decomposition of the complex is seen above $420{ }^{\circ} \mathrm{C}$. The residual mass was found to be $29.68 \%$ which corresponds metal oxide formed after the decomposition of complex.

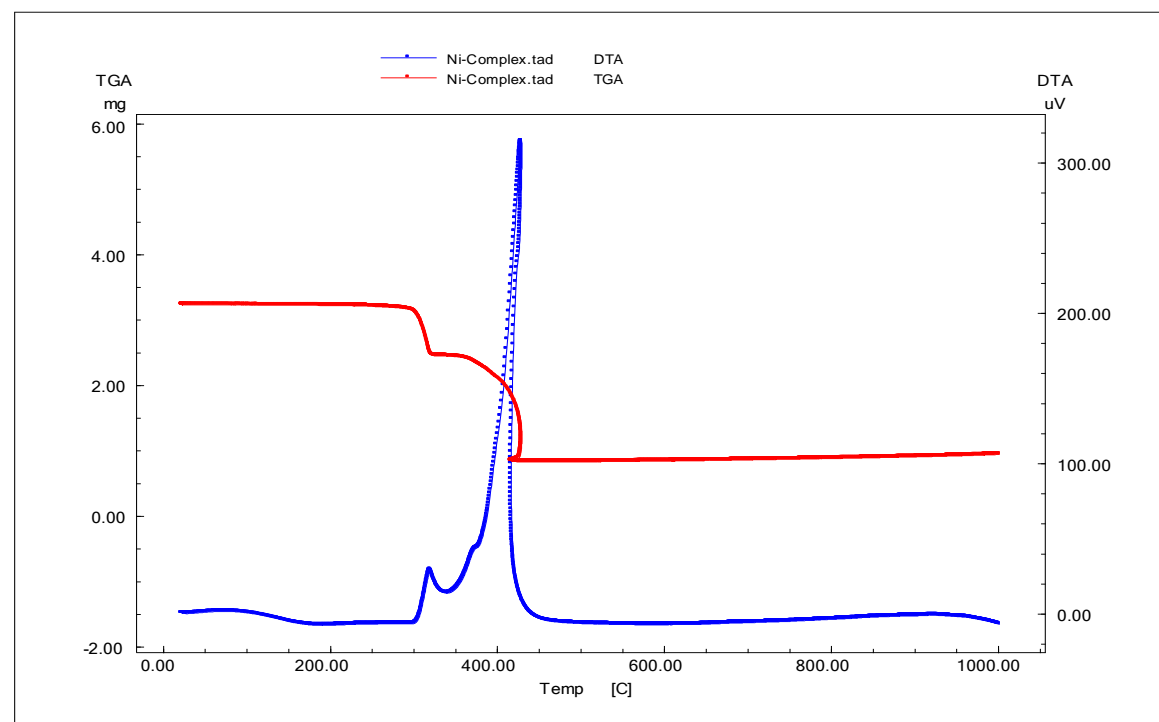

Figure 17: TGA and DTA curves of Ni (II) PTP complex.

\subsubsection{Magnetic susceptibility}

The magnetic susceptibilities were measured at room temperature. The effective magnetic moment values calculated for $\mathrm{Cu}$ (II) PTP and Ni (II) PTP were found to be 1.49 and 3.1 BM respectively. These values indicate square planar environment for copper (II) complex and octahedral for $\mathrm{Ni}$ (II) complex.

\subsection{Computational studies}

In the present investigation the HyperChem 7.5 software was used for quantum mechanical calculations to generate spectral data. After building molecule by HyperChem tools [26-30], the geometry optimization was carried out using semi empirical PM3 method. The IR spectral data is generated and compared with the experimental data. 
QSAR properties permit calculation and estimation of a variety of molecular descriptors generally used in quantitative structure activity relationship (QSAR) studies [31-32]. Quantum chemical calculations have been widely used to study donor and acceptor properties of molecules. The values of energy of the highest occupied molecular orbitals $\left(E_{\mathrm{HOMO}}\right)$, energy of the lowest unoccupied molecular orbitals $\left(E_{\mathrm{LUMO}}\right)$ and the energy gap between them $\left(E_{\text {LUMO-Hомо }}\right)$ of PTP molecule were computed. The energies of HOMO and LUMO frontier orbitals computed for the optimized charged molecule (Fig 18) and neutral molecule (Fig 19) indicate that PTP possess potential electron donor sites.

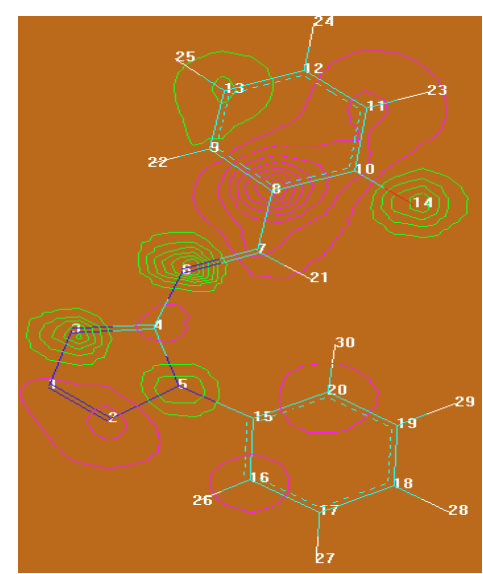

HOMO (-4.244eV)

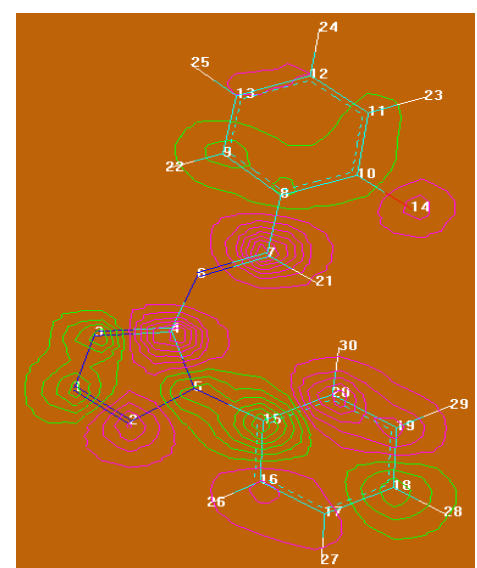

LUMO (1.831eV)

Figure 18: Highest occupied molecular orbital (HOMO) and Lowest unoccupied molecular orbital (LUMO) of charged PTP

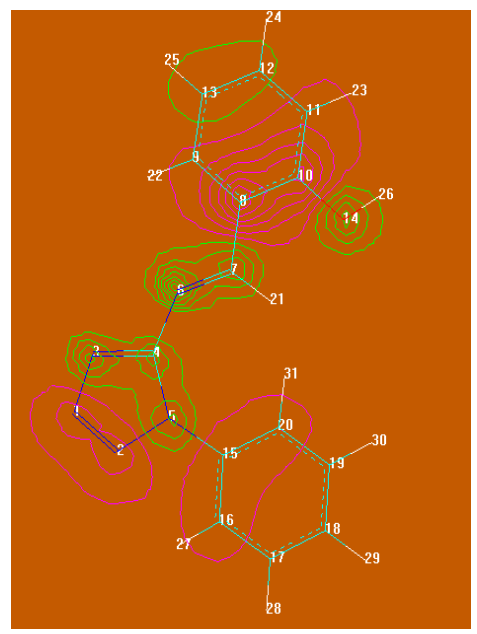

HOMO (-9.31eV)

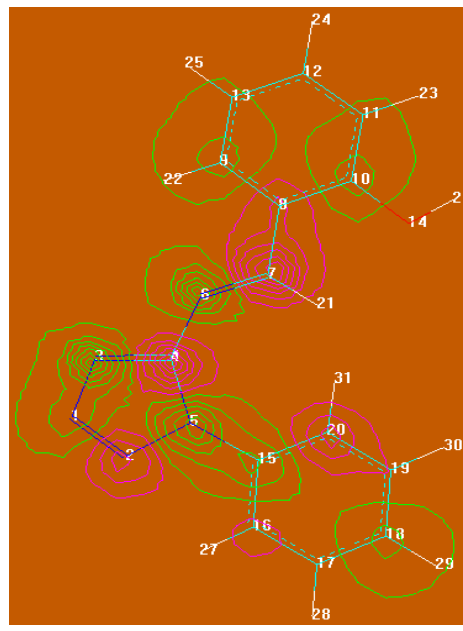

LUMO (-1.452eV)

Figure 19: Highest occupied molecular orbital (HOMO) and Lowest unoccupied molecular orbital (LUMO) of Neutral PTP molecule

\subsubsection{QSAR and Molecular properties of PTP}

Quantitative structure-activity relationship (QSAR) is a computational process that explains the chemical structure of compounds with their activities, especially biological activities. QSAR properties like surface area, volume, hydration energy, $\log \mathrm{P}$, refractivity, polarizability, mass, total energy etc. and other molecular properties have been computed for geometry optimized structure of title compound (Table 2). 
Table 2: QSAR properties of PTP.

\begin{tabular}{|l|l|}
\hline QSAR properties & \\
\hline Surface area & $394.24 \AA^{2}$ \\
\hline Volume & $767.62 \AA^{3}$ \\
\hline Hydration energy & $-20.74 \mathrm{kcal} / \mathrm{mol}$ \\
\hline Log P & 5.23 \\
\hline Refractivity & $79.20 \AA^{3}$ \\
\hline Polarisability & $28.21 \AA^{3}$ \\
\hline Mass & $265.64 \mathrm{amu}$ \\
\hline Molecular properties & $-67535.9 \mathrm{kcal} / \mathrm{mol}$ \\
\hline Total energy & $8.08 \mathrm{D}$ \\
\hline Dipole moment & \\
\hline
\end{tabular}

\subsubsection{Vibrational Analysis}

HyperChem calculates all of the fundamental modes, both IR and Raman, as well as the IR intensities. The experimental spectral data are compared with the data generated by semi empirical single point (PM3 method) and were found to be in good agreement with each other (Table 3).

Table 3: IR Spectral data of PTP

\begin{tabular}{|c|c|c|c|c|}
\hline & $\boldsymbol{v}_{\mathbf{O H}}$ & $\boldsymbol{v}_{\mathbf{C H}}$ aro & $\boldsymbol{v}_{\mathbf{C}=\mathbf{N}}$ & $\boldsymbol{v}_{\mathbf{C}=\mathbf{C}(\text { ring })}$ \\
\hline Experimental & 3492 & 3062 & 1666 & 1604 \\
\hline Computational & 3882 & 3074 & 1843,1636 & 1789 \\
\hline
\end{tabular}

\subsubsection{NMR Spectral Simulation of PTP}

${ }^{1} \mathrm{H}-\mathrm{NMR}$ is generated by Hyper NMR and is compared with the experimentally obtained spectral data. On comparison, the values were found to be in good accordance with each other (Table 4).

Table 4: ${ }^{1} \mathrm{H}-\mathrm{NMR} \delta(\mathrm{ppm})$ Spectral data

\begin{tabular}{|l|c|c|c|}
\hline & $\boldsymbol{\delta}(\mathbf{H C}=\mathbf{N})$ & $\boldsymbol{\delta}$ ring $(\mathbf{O H})$ & $\boldsymbol{\delta}$ aromatic $\mathbf{C H}$ \\
\hline Experimental & 9.25 & 11.5 & $7.1-8.2$ \\
\hline Computational & 9.5 & & 6.75 \\
\hline
\end{tabular}

\subsection{Antimicrobial activity:}

Actively growing microbial cultures viz; Gram positive (Staph aureus and Bacillus), Gram negative (Escherichia coli, Pseudomonas and Klebsiella), and Yeast (Saccharomyces cerevisiae) were spread on nutrient agar ( $1 \%$ beef extract, $1 \%$ peptone, $0.5 \% \mathrm{NaCl}$ and $1.5 \%$ agar agar) and yeast extract peptone dextrose agar (1\% yeast extract, $2 \%$ dextrose and $1.5 \%$ agar agar) medium respectively. Wells were created on agar plates by using sterile $6 \mathrm{~mm}$ diameter well borer. Then $20 \mu \mathrm{l}$ each of imine base and its copper complex with concentration of $5 \mathrm{mg} / 1 \mathrm{ml}$ were inoculated into the wells. After inoculation, the petri dishes were placed in refrigerator for $15 \mathrm{~min}$, and then incubated at $37{ }^{\circ} \mathrm{C} / 24 \mathrm{hrs}$ and $30{ }^{\circ} \mathrm{C} / 48 \mathrm{hrs}$ respectively. After incubation, the antimicrobial activity was measured by the zone of inhibition around the wells in millimeters. The activity of copper - PTP complex is relatively more than free PTP indicating enhanced antimicrobial activity in complex (Table 5). 
Table 5: Antibacterial and antifungal activity of PTP and its $\mathrm{Cu}$ (II) complex:

\begin{tabular}{|l|c|c|}
\hline \multicolumn{1}{|c|}{ Name of the Organism } & PTP & Cu(II)PTP \\
\hline Staphylo coccus aureus & - & 5 \\
\hline Bacillus cereus & - & 5 \\
\hline Pseudomonas aeruginosa & 6 & $\mathbf{8}$ \\
\hline E.Coli & - & 4 \\
\hline Klebsiella pnemoniae & - & 7 \\
\hline Yeast & - & 6 \\
\hline
\end{tabular}

\subsection{DNA cleavage:}

DNA is an important substrate for hydrolytic cleavage. Because of its poly anionic nature DNA is resistant to hydrolysis. Super coiled (SC) plasmid DNA is an important substrate. This particular form of DNA, which is commonly observed in bacteria cells, is a cyclic super coiled double strand made up of several thousand base pairs. By coordinating to this substrate, metal ions serve as a lewis acids to activate the phosphodiester for nucleophillic attack. The metal coordinated water $\mathrm{M}-\mathrm{OH}$ species acts as a nucleophile to attack the SC DNA form (I). Then SC DNA is relaxed to nicked circular form (II) and further cleaved to linear form (III). When subjected to electrophoresis, relatively fast migration is observed for form (I), slow migration for form (II) and form (III). In the present investigation, DNA cleavage is not observed with PTP and Ni (II)-PTP complex but DNA hydrolytic cleavage is more pronounced in the presence of $\mathrm{Cu}$ (II) PTP (Fig 20).

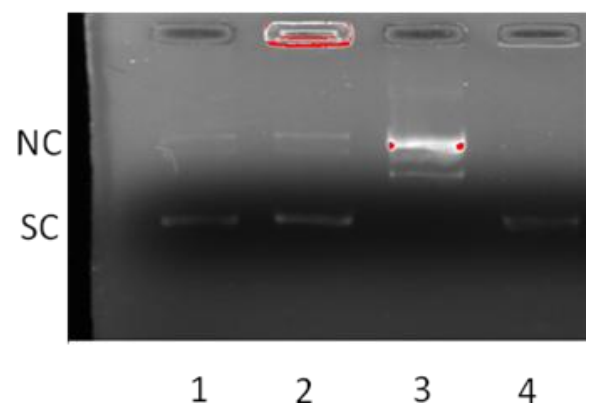

Figure 20: DNA cleavage activity of PTP, Cu (II) PTP and Ni (II) PTP

Lane 1: DNA marker $(1 \mu \mathrm{l}+4 \mu \mathrm{l}$ Tris - HCl Buffer $)$ Lane 2: DNA $(1 \mu \mathrm{l}+4 \mu \mathrm{l}$ Tris - HCl Buffer $)+$ PTP $(5 \mu l$ of $2 \mathrm{mg} / \mathrm{ml})$ Lane 3: DNA (1 $\mu \mathrm{l}+4 \mu \mathrm{l}$ Tris $-\mathrm{HCl}$ Buffer $)+\mathrm{Cu}$ (II) PTP (5 $\mu \mathrm{l}$ of $2 \mathrm{mg} / \mathrm{ml})$ Lane 4: DNA $(1 \mu \mathrm{l}+4 \mu \mathrm{l}$ Tris - HCl Buffer $)+\mathrm{Ni}$ (II) PTP $(5 \mu \mathrm{l}$ of $2 \mathrm{mg} / \mathrm{ml})$

\section{CONCLUSIONS}

New imine base (PTP) and its $\mathrm{Cu}$ (II) and Ni (II) complexes were synthesized and characterized by the data obtained from various spectro-analytical techniques. Quantum mechanical calculations were also carried out on the title compound using 7.5 HyperChem. The molecule was built and the geometry optimization was carried out using PM3 method. The studies on antibacterial activity inferred that $\mathrm{Cu}$ (II)-PTP complex is more effective than PTP and Ni (II)-PTP complex. Plasmid cleavage activity was ascertained by GelElectrophoresis mobility assay. The results inferred that $\mathrm{Cu}$ (II)-PTP is more effectual in the cleavage of plasmid PBR-322 DNA Super coiled Form (I) and consequently resulting Nicked circular form(II) of DNA.

\section{ACKNOWLEDGEMENTS:}

We are grateful to Council of Scientific and Industrial Research for generous financial support to one of the author Palreddy Ranjith Reddy Osmania University, Hyderabad. We are thankful to the Instrumentation Lab Facilities, Department of Chemistry and the Department of Central Facilities for Research \& Development (CFRD), Osmania University, Hyderabad for recording UV-Vis, IR and ${ }^{1} \mathrm{H}-\mathrm{NMR}$ spectra. We are also thankful to Department of Microbiology, Osmania University for providing necessary facilities. 


\section{REFERENCES}

[1] Wittenberger, S. Journal of Organic Preparations and Procedures International 26, 1994, 499.

[2] Ford, R. E.; Knowles, P.; Lunt, E.; Marshall, S. M.; Penrose, A. J.; Ramsden, C. A.; a. Summers, A. J. H.; Walker, J. L.; Wright, D. European Journal of Medicinal Chemistry ,29, 1986, 538.

[3] Peet, N. P.; Baugh, L. E.; Sundler, S.; Lewis, J. E.; Matthews, E. H.; Olberding, E. L.; a. Shah, D. N. Journal of Medicinal Chemistry, 29, 1986, 2403.

[4] Girijavallabhan, V.M.; Pinto, P.A.; Genguly, A.K.; Versace, R.W. European Patent EP a . 274,867, 1988; Chemical Abstract, 1989,11023890 .

[5] (a) Akimoto, H.; Ootsu, K.; Itoh, F. European Patent EP 530,537, 1993; Chemical abstract a. 119, 1993, 226417. (b) Taveras, A.G.; Mallams, A.K.; Afonso, A. International Patent WO b. 9,811,093, 1998; Chemical abstract 128, $1998,230253$.

[6] Mitch, C.H.; Quimby, S.J. International PatentWO 9,851,312, 1998; Chemical abstract, 130, a ,1998. 13997.

[7] Ek, F.; Wistrand, L.-G.; Frejd, T. Tetrahedron 59, 2003, 6759.

[8] Flippin, L. A. Tetrahedron Letters, 32, 1991, 6857.

[9] Rhonnstad, P.; Wensbo, D. Tetrahedron Letters, 43, 2002, 3137.

[10] Jursic, B. S.; LeBlanc, B. W. Journal of Heterocyclic Chemistry 35, 1998, 405.

[11] John, E. O.; Kirchmeier, R. L.; Shreeve, J. M. Inorgnic chemistry 28, 1989, 4629.

[12] Zhao-Xu, C.; Heming, X. International Journal of Quantum Chemistry 79, $2000,350$.

[13] Wood, E.; Crosby, R. M.; Dickerson, S.; Frye, S. V.; Griffin, R.; Hunter, R. Anti Cancer Drug Design 16, $2001,1-6$.

[14] May, B. C. H.; Abell, A. D Journal of chemical society, Perkin Trans. 2 2002, 172-178.

[15] Y.-C. Liu, Z.-F. Chen, L.-M. Liu, Y. Peng, X. Hong, B. Yang, H.-G. Liu, H. Liang, i. Orvig, Dalton Trans, $2009,10813$.

[16] E.-J. Gao, Q. Wu, C.-S. Wang, M.-C. Zhu, L. Wang, H.-Y. Liu, Y. Huang, Y.-G. Sun, i. Journal of coordination chemistry, 62, $2009,3425$.

[17] N. Raman, A. Sakthivel, R. Jeyamurugan, Journal of coordination chemistry, 62, $2009,3969$.

[18] Irving H.M. \& Rossotti H.S.; Journal of chemical society, 1954, 2904.

[19] Irving H.M and Rossetti H.S.; Journal of chemical society, 1953, 3397.

[20] Irving H.M and Rossotti H.S.; Acta Chemica Scandinavica, . 10, 1956, 72.

[21] Laxmi K., Bhargavi G., Sireesha B. and Sarala Devi Ch.; Bulletin of the Chemical Society of Ethiopia,20(1) ,2006, 161.

[22] Bhargavi G., Sireesha B. and Sarala Devi Ch.; Bulletin of pure and applied sciences 21C (No.1),2002, p 1.

[23] Bhargavi G., Sireesha B. and Sarala Devi Ch.; Journal of the Indian Chemical Society, 79, $2002,826$.

[24] Sireesha B. Bhargavi G., Sita C. and Sarala Devi Ch.; Bulletin of Pure and Applied Sciences, 25C ,2006, 1.

[25] Aliya, Sireesha B., Venkataramana Reddy Ch. and Sarala Devi Ch.; Journal of the Indian Chemical Society, 85, $2008,926$.

[26] A. Broo, Per Lincoln, Ab-initio and Semi empirical Calculations of Geometry and Electronic Spectra of Ru complexes and Modeling DNA Binding, Inorganic chemistry, 36, 1997, 2544-2553.

[27] R. K. Gilpin, Predicting ID NMR Spectra-HyperNMR, Analytical Chemistry, 67, (17A), $1995,541$.

[28] O. Vanciuc, Hyperchem Release 4.5 for Windows, Journal of Chemical Information and Computer Sciences., 36, 3, 1996, 612614.

[29] W. R.Winchester and M. P. Doyle, HyperChem, Journal of the American Chemical Society. 114, 23,1992, 9243.

[30] W. Witanowski et al, Solvent effects on the nitrogen NMR shieldings in oxadiazole systems, Journal of Magnetic Resonance120, 2, 1996, 148-154.

[31] C. Hansch, A. Leo and D. H. Hoekman, Exploring QSAR, Fundamentals and applications in Chemistry and Biology, American Chemical Society Washington, DC, USA, 1995.

[32] A. K. Srivastava, M. Jaiswal, Archana and A. Srivastava, , Journal of Magnetic Resonance, 32, 2009,55 . 